\title{
The Transition of Poised RNA Polymerase II to an Actively Elongating State Is a "Complex" Affair
}

\author{
Marie N. Yearling, Catherine A. Radebaugh, and Laurie A. Stargell \\ Biochemistry and Molecular Biology, Colorado State University, Fort Collins, CO 80523-1870, USA \\ Correspondence should be addressed to Laurie A. Stargell, laurie.stargell@colostate.edu
}

Received 24 June 2011; Accepted 31 July 2011

Academic Editor: Sebastián Chávez

Copyright ( $\odot 2011$ Marie N. Yearling et al. This is an open access article distributed under the Creative Commons Attribution License, which permits unrestricted use, distribution, and reproduction in any medium, provided the original work is properly cited.

\begin{abstract}
The initial discovery of the occupancy of RNA polymerase II at certain genes prior to their transcriptional activation occurred a quarter century ago in Drosophila. The preloading of these poised complexes in this inactive state is now apparent in many different organisms across the evolutionary spectrum and occurs at a broad and diverse set of genes. In this paper, we discuss the genetic and biochemical efforts in S. cerevisiae to describe the conversion of these poised transcription complexes to the active state for productive elongation. The accumulated evidence demonstrates that a multitude of coactivators and chromatin remodeling complexes are essential for this transition.
\end{abstract}

\section{Introduction}

RNA Polymerase II (RNAPII) is a 12-subunit enzyme that binds promoter DNA and catalyzes the synthesis of messenger RNA in eukaryotes. Although the recruitment of RNAPII to a promoter is necessary for productive gene expression, it is not sufficient in many cases. Early studies in Drosophila [1] and more recent genome-wide analyses in both flies and humans have revealed that thousands of genes contain poised RNAPII at their promoters [2-5]. These poised promoters allow for rapid and synchronous activation, thereby providing the precise timing of gene expression critical for developmental processes $[6,7]$. Indeed, postrecruitment events necessary to convert RNAPII into a productively elongating form are increasingly considered general regulatory features of transcription in higher eukaryotes [8-10].

In yeast cultured to stationary phase, approximately $40 \%$ of the genes in the genome show association of RNAPII in their inactive state [11]. These polymerases are thought to be poised for rapid and concerted activation upon transition to more opportunistic growth conditions. In actively growing yeast cultures, genome-wide studies indicate that partial but inactive PIC complexes are a widespread phenomenon across the genome [12] and a majority of bound RNAPII may be in an inactive state $[11,13]$. Gene regulation at postrecruitment steps in $S$. cerevisiae is also supported by differences in $5^{\prime}$ to $3^{\prime}$ RNAPII occupancy and the frequent pausing of RNAPII within coding regions of genes [14, 15]. In addition, accumulation of inactive RNAPII within ribosomal protein genes [16] and at the promoter of the uninduced CYC1 gene [17] provides further support for postrecruitment transcriptional regulation in yeast. Due to the genetic and biochemical amenability of the yeast system, studies of the transition of poised RNAPII to the active form have provided key insights into the sophisticated molecular requirements involved in this postrecruitment process.

\section{The Yeast CYC1 Gene: A Model for Postrecruitment
Regulation via Poised RNAPII}

The yeast CYC1 gene encodes iso-1-cytochrome c, a nuclearencoded protein involved in the electron transport chain in the mitochondria [18]. In the presence of a fermentable carbon source (such as dextrose), CYC1 gene expression is extremely low $[19,20]$. When cells are grown on a nonfermentable carbon source (such as lactate or ethanol), CYC1 is activated and transcript levels increase 10-fold. In contrast to the dramatic changes in transcriptional output, 
the occupancy of RNAPII $[17,21]$, as well as a number of other factors $[22,23]$, is maintained during the carbon source change (Figure 1). The CYC1 promoter contains preloaded RNAPII, the general transcription factors TATAbinding protein (TBP) and TFIIH, the SAGA (Spt-AdaGcn5 acetyltransferase) complex, and Spn1, a highly conserved chromatin-associated transcription factor [22, 23]. Intriguingly, RNAPII is serine 5 phosphorylated on the Cterminal domain (CTD) of Rpb1 prior to activation [23]. The CTD is hypophosphorylated prior to initiation and typically becomes serine 5 hyperphosphorylated during the transition from initiation to elongation $[24,25]$. The phosphorylation of the CTD at CYC1 prior to activation is consistent with TFIIH occupancy, since TFIIH has CTD kinase as well as DNA unwinding activities [26-30]. Under inducing conditions for $C Y C 1$, a number of new factors are recruited to the promoter including the Mediator complex, and the chromatin regulatory factors the Swi/Snf complex and Spt6 [22]. This poised promoter could be advantageous in the native environment, allowing for rapid induction due to changing nutritional needs [31].

\section{The Role of SAGA in the Inactive-to-Active Transition}

The SAGA complex is a large multisubunit coactivator that facilitates gene expression at multiple steps within the transcription cycle [32, 33], including initiation [34-42] and more recently identified activities in the stimulation of elongation [33]. SAGA localization within gene coding regions [43-47] and elongation defects in SAGA deficient strains $[46,48,49]$ demonstrate that the function of SAGA in transcription activation extends beyond the well-characterized activities of TBP delivery and posttranslational modifications of histones. It is unclear how the emerging functions in elongation pertain to the traditional roles of SAGA except at CYC1, where studies indicate that they appear to be functionally distinct.

The poised CYC1 promoter requires SAGA for the transition from a preloaded complex to an actively transcribing unit since deletion of SAGA-integrity subunits blocks activated transcription [22]. Several well-characterized functions of SAGA are not relevant to this transition. For example, SAGA contains a TBP interaction module essential for delivering TBP to certain promoters [34-38]. Since the preloaded promoter has both TBP and SAGA present under noninducing conditions, a functional connection between the two seemed likely. Surprisingly, although abolishing the SAGA complex results in loss of activated transcription, it does not alter TBP occupancy [22]. SAGA also has two known histone modifying enzymatic capabilities, a histone acetyltransferase (HAT) module responsible for acetylation events involved in facilitating active transcription [39-42] and a histone deubiquitinase (DUB) module known to aid in elongation $[50,51]$. Yet, strains deficient for HAT activity or the DUB module are competent for activation [22].

In summary, the preloaded promoter is not dependent on the traditional well-characterized roles of SAGA, and yet SAGA integrity is required for the transition to an actively elongating complex after the recruitment of the PIC. These elongation activities may also be important at other genes, but difficult to observe because those genes require SAGA for recruitment of the general transcription machinery. The functions of numerous components within the SAGA complex remain to be elucidated and the preloaded promoter provides an excellent archetype for further investigations. Despite the necessity for SAGA function, SAGA is not sufficient for activation and another coactivator is critical for induction of the poised promoter.

\section{Mediator-RNAPII Connections at CYCI}

The Mediator complex is a large coactivator that is conserved from yeast to humans [52] and acts as an integrator of the transcription process, traditionally linking upstream signals from the activator with the general transcription machinery [53-57]. Mediator is essential for CYC1 activation and is recruited after the transfer to inducing conditions [22]. Mediator is well characterized for its ability to recruit RNAPII to promoters $[57,58]$, although this function is unnecessary for CYC1 since RNAPII is present at the poised promoter prior to activation. Mediator has also been shown to stimulate TFIIH-dependent phosphorylation of the CTD [57, 59]. However, as previously noted, serine 5 phosphorylation of the CTD at CYC1 is observed prior to activation when Mediator is absent from the promoter, although subsequent rounds of transcription may be impacted. Mediator has also been shown to be involved in the isomerization of the PIC into a transcriptionally competent conformation [60]. This function fits well with the Mediator requirement for activation of the poised promoter as the subunits of Mediator essential for activating the poised promoter [22] are involved in interactions with RNAPII and the general transcription factors $[54,57,61]$.

\section{Chromatin Components with Critical Roles in the Transition to Active RNAPII}

The transition of the poised promoter to its actively elongating form is highly dependent on a number of chromatin regulatory factors, including the Spn1/Spt6 [62, 63] complex and the Swi/Snf complex [23]. Notably, RNAPII and Spn1 occupy the poised promoter in the uninduced state, whereas Spt6 and Swi/Snf are recruited upon activation (Figure 1). Spn1 interacts with both RNAPII and Spt6 [23, 64-69], thereby linking the regulation of the poised promoter to the chromatin architecture. Spt6 is a histone chaperone that promotes reassembly of nucleosomes following passage of RNAPII [70-74], and Spn1 is an important regulator of the Spt6-nucleosome interaction [75]. In addition to a nucleosome maintenance role during elongation, Spt6 also has other chromatin-dependent [76] and chromatin-independent [77] roles in transcription. Importantly, the loss of Spn1 at CYC1 under noninducing conditions leads to a failure to recruit Spt6 under inducing conditions [23], consistent with their direct interaction $[75,78]$. Mutations 


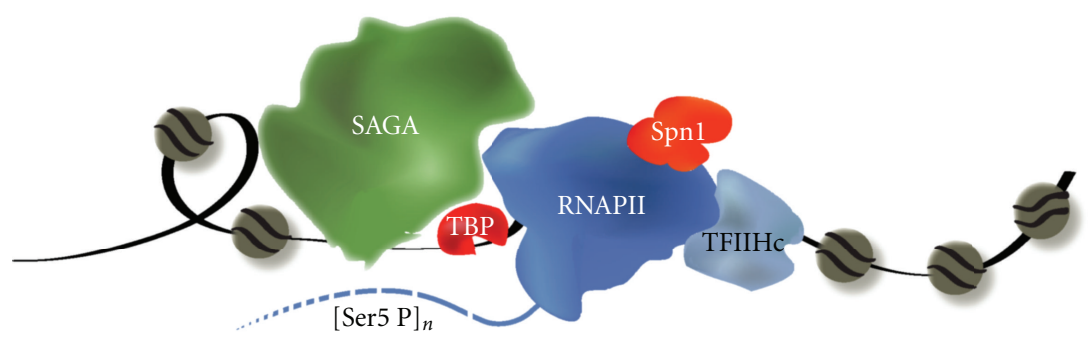

(a)

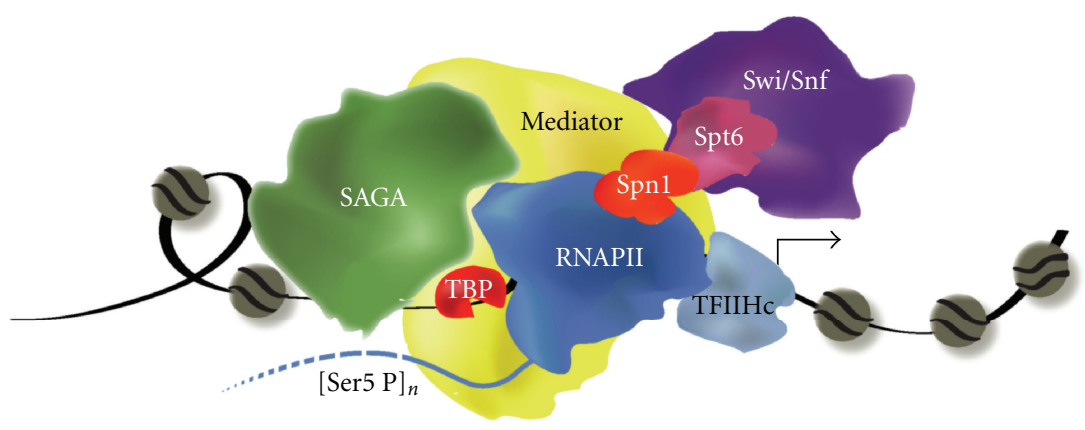

(b)

FIGURE 1: The poised CYC1 promoter contains preloaded transcription components. (a) Prior to activation, the preloaded CYC1 promoter contains TATA binding protein (TBP), RNA polymerase II (RNAPII), the core TFIIH complex (TFIIHc), Spt-Ada-GCN5 acetyltransferase (SAGA), and the transcription factor Spn 1 . The CTD, shown by the hashed line trailing RNAPII exhibits serine 5 phosphorylation potentially on multiple repeats (denoted by " $n$ "). These components occupy the promoter prior to high levels of transcriptional output. (b) The occupancy of the preloaded factors is maintained under induced conditions, and Mediator, Spt6, and Swi/Snf are recruited, leading to an increase in transcriptional output (indicated by the arrow).

in either Spt6 [70, 79] or Spn1 [23] suppress mutant phenotypes associated with the loss of the Swi/Snf complex.

Swi/Snf is an ATP-dependent chromatin remodeler that disassembles nucleosomes resulting in a loss of histones from DNA [80]. Swi/Snf is involved in remodeling at several recruitment-regulated promoters [81-84] as well as in coding regions $[85,86]$. Suppressing mutations as observed for Spn1, Spt6, and Swi/Snf are typical indicators of factors that function in the same pathway and are physically connected [87, 88]. Specifically at CYC1, the absence of promoter binding by Spn1 results in constitutive recruitment of the Swi/Snf complex [23]. Thus, the binding of Spn1 blocks the recruitment of the Swi/Snf complex in the uninduced state and also serves as a platform for recruiting Spt6 during the activated state. An attractive model for the functions of these factors in proper CYC1 expression is that, in order for the transition to an actively elongating state to occur, the Swi/Snf complex evicts nucleosomes and the Spn1/Spt6 complex reassembles them. Precisely how these activities are related to the poised RNAPII in the uninduced state remains to be investigated, but it is tempting to speculate that the interplay between RNAPII and the nucleosomal architecture contributes to the inactive state. The involvement of the chromatin context and inactive RNAPII complexes has also been observed at particular silent loci in the yeast genome [89].

\section{Poising as a "Complex" Affair}

Several important questions remain. For example, what creates the poised polymerase in the first place? We have found that the occupancy of RNAPII at CYC1 is an incredibly robust phenomenon: single deletion of dozens of different transcription factors and coactivator complex subunits has not resulted in RNAPII occupancy defects (data not shown and [22]). It could be that RNAPII preloading is an intrinsic property of the CYC1 promoter and/or its nuclear and chromosomal context. In contrast to the resiliency of RNAPII occupancy, the transition to an actively elongating form is a highly demanding phenomenon, requiring the efforts of several prodigious and powerful transcription complexes: SAGA, Mediator, and Swi/Snf. Intriguingly, these complexes and their functions appear to work autonomously at CYC1. As shown previously [22], Mediator and SAGA occupancy are not dependent on each other, and mutations that result in constitutive occupancy of Swi/Snf do not bypass the need for SAGA or Mediator for activation of the preloaded promoter (Figure 2). As such, three distinct pathways are required to shift the polymerase into its active form. Further studies are needed to elucidate how each complex directly contributes to the transition from the poised to the active form. However, it is clear that in accordance with Newton's first law (a body at rest tends to stay at rest), these large macromolecular 


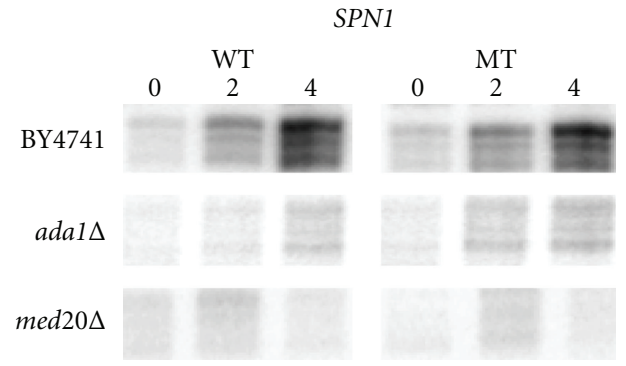

Figure 2: Mutating SPN1, which results in loss of Spn1 and constitutive recruitment of Swi/Snf to the promoter, does not bypass the requirement for SAGA or Mediator. CYC1 transcript levels were analyzed before and two or four hours after induction in ethanol using an S1 nuclease protection assay [23] with RNA isolated from wild-type, ada1 $\Delta$ or med20 $\Delta$ strains. Each strain harbors either a wild-type (WT) or mutant (MT) form of SPN1. Similar results were obtained for other SAGA and Mediator deletion strains, including

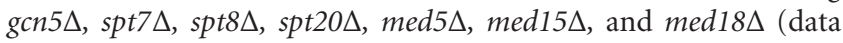
not shown).

assemblies must provide the essential outside forces to initiate the process.

\section{Perspectives}

How related is the RNAPII poising observed in yeast to that in metazoans? Studies in flies and human cells have clearly established that in many cases the polymerase has started transcribing and is paused just downstream of the start site. In contrast, there is no evidence for initiated transcripts that are stalled in yeast $[13,90]$. Whether the poised RNAPII in yeast is an evolutionary precursor to the more sophisticated version of paused RNAPII in metazoans is an open question. Nevertheless, it is intriguing that occupancy of SAGA [47, 91], a requirement for Mediator [53, 60, 92], a dependency on Spt6 [74], the involvement of Spn1 [73], and the chromatin architecture [93] play critical roles in pausing and/or postrecruitment transcriptional events in metazoan cells. Taken together, these results suggest that there are universal requirements for the activities of multiple complexes in the transition of RNAPII from a poised to an actively elongating state.

\section{Acknowledgments}

The authors would like to thank Adam Almeida, Sarah Lee, and Tingting Yao for critical reading and feedback. The work in the Stargell laboratory is supported by grants to L.A.S. from the National Science Foundation (MCB-0843073) and National Institutes of Health (GM088409).

\section{References}

[1] D. S. Gilmour and J. T. Lis, "RNA polymerase II interacts with the promoter region of the noninduced hsp70 gene in Drosophila melanogaster cells," Molecular and Cellular Biology, vol. 6, no. 11, pp. 3984-3989, 1986.
[2] T. H. Kim, L. O. Barrera, M. Zheng et al., "A high-resolution map of active promoters in the human genome," Nature, vol. 436, no. 7052, pp. 876-880, 2005.

[3] M. G. Guenther, S. S. Levine, L. A. Boyer, R. Jaenisch, and R. A. Young, "A chromatin landmark and transcription initiation at most promoters in human cells," Cell, vol. 130, no. 1, pp. 77-88, 2007.

[4] G. W. Muse, D. A. Gilchrist, S. Nechaev et al., "RNA polymerase is poised for activation across the genome," Nature Genetics, vol. 39, no. 12, pp. 1507-1511, 2007.

[5] I. M. Min, J. J. Waterfall, L. J. Core, R. J. Munroe, J. Schimenti, and J. T. Lis, "Regulating RNA polymerase pausing and transcription elongation in embryonic stem cells," Genes and Development, vol. 25, no. 7, pp. 742-754, 2011.

[6] J. Zeitlinger, A. Stark, M. Kellis et al., "RNA polymerase stalling at developmental control genes in the Drosophila melanogaster embryo," Nature Genetics, vol. 39, no. 12, pp. 1512-1516, 2007.

[7] R. N. Saha, E. M. Wissink, E. R. Bailey et al., "Rapid activityinduced transcription of Arc and other IEGs relies on poised RNA polymerase II," Nature Neuroscience, vol. 14, no. 7, pp. 848-856, 2011.

[8] L. A. Selth, S. Sigurdsson, and J. Q. Svejstrup, "Transcript elongation by RNA polymerase II," Annual Review of Biochemistry, vol. 79, pp. 271-293, 2010.

[9] M. Levine, "Paused RNA polymerase II as a developmental checkpoint," Cell, vol. 145, no. 4, pp. 502-511, 2011.

[10] S. Nechaev and K. Adelman, "Pol II waiting in the starting gates: regulating the transition from transcription initiation into productive elongation," Biochimica et Biophysica Acta, vol. 1809, no. 1, pp. 34-45, 2011.

[11] M. Radonjic, J. C. Andrau, P. Lijnzaad et al., "Genome-wide analyses reveal RNA polymerase II located upstream of genes poised for rapid response upon $S$. cerevisiae stationary phase exit," Molecular Cell, vol. 18, no. 2, pp. 171-183, 2005.

[12] S. J. Zanton and B. F. Pugh, "Full and partial genome-wide assembly and disassembly of the yeast transcription machinery in response to heat shock," Genes and Development, vol. 20, no. 16, pp. 2250-2265, 2006.

[13] V. Pelechano, S. Chávez, and J. E. Pérez-Ortín, "A complete set of nascent transcription rates for yeast genes," PLOS ONE, vol. 5, no. 11, Article ID e15442, 2010.

[14] B. J. Venters and B. F. Pugh, "A canonical promoter organization of the transcription machinery and its regulators in the Saccharomyces genome," Genome Research, vol. 19, no. 3, pp. 360-371, 2009.

[15] L. S. Churchman and J. S. Weissman, "Nascent transcript sequencing visualizes transcription at nucleotide resolution," Nature, vol. 469, no. 7330, pp. 368-373, 2011.

[16] V. Pelechano, S. Jimeno-González, A. Rodríguez-Gil, J. GarcíaMartínez, J. E. Pérez-Ortín, and S. Chávez, "Regulon-specific control of transcription elongation across the yeast genome," PLoS Genetics, vol. 5, no. 8, Article ID e1000614, 2009.

[17] C. Martens, B. Krett, and P. J. Laybourn, "RNA polymerase II and TBP occupy the repressed CYC1 promoter," Molecular Microbiology, vol. 40, no. 4, pp. 1009-1019, 2001.

[18] F. Sherman, J. W. Stewart, E. Margoliash, J. Parker, and W. Campbell, "The structural gene for yeast cytochrome C," Proceedings of the National Academy of Sciences of the United States of America, vol. 55, no. 6, pp. 1498-1504, 1966.

[19] L. Guarente and T. Mason, "Heme regulates transcription of the CYC1 gene of S. cerevisiae via an upstream activation site," Cell, vol. 32, no. 4, pp. 1279-1286, 1983.

[20] L. Guarente, B. Lalonde, P. Gifford, and E. Alani, "Distinctly regulated tandem upstream activation sites mediate catabolite 
repression of the CYC1 gene of S. cerevisiae," Cell, vol. 36, no. 2, pp. 503-511, 1984.

[21] L. Kuras and K. Struhl, "Binding of TBP to promoters in vivo is stimulated by activators and requires Pol II holoenzyme," Nature, vol. 399, no. 6736, pp. 609-613, 1999.

[22] S. K. Lee, A. G. L. Fletcher, L. Zhang, X. Chen, J. A. Fischbeck, and L. A. Stargell, "Activation of a poised RNAPII-dependent promoter requires both SAGA and mediator," Genetics, vol. 184, no. 3, pp. 659-672, 2010.

[23] L. Zhang, A. G. L. Fletcher, V. Cheung, F. Winston, and L. A. Stargell, "Spn1 regulates the recruitment of Spt6 and the Swi/Snf complex during transcriptional activation by RNA polymerase II," Molecular and Cellular Biology, vol. 28, no. 4, pp. 1393-1403, 2008.

[24] P. Komarnitsky, E. J. Cho, and S. Buratowski, "Different phosphorylated forms of RNA polymerase II and associated mRNA processing factors during transcription," Genes and Development, vol. 14, no. 19, pp. 2452-2460, 2000.

[25] C. Cheng and P. A. Sharp, "RNA polymerase II accumulation in the promoter-proximal region of the dihydrofolate reductase and $\gamma$-actin genes," Molecular and Cellular Biology, vol. 23, no. 6, pp. 1961-1967, 2003.

[26] W. J. Feaver, O. Gileadi, Y. Li, and R. D. Kornberg, "CTD kinase associated with yeast RNA polymerase II initiation factor b," Cell, vol. 67, no. 6, pp. 1223-1230, 1991.

[27] H. Lu, L. Zawel, L. Fisher, J. M. Egly, and D. Reinberg, "Human general transcription factor IIH phosphorylates the Cterminal domain of RNA polymerase II," Nature, vol. 358, no. 6388, pp. 641-645, 1992.

[28] H. Serizawa, R. C. Conaway, and J. W. Conaway, "A carboxylterminal-domain kinase associated with RNA polymerase II transcription factor d from rat liver," Proceedings of the $\mathrm{Na}$ tional Academy of Sciences of the United States of America, vol. 89, no. 16, pp. 7476-7480, 1992.

[29] H. Serizawa, J. W. Conaway, and R. C. Conaway, "Phosphorylation of C-terminal domain of RNA polymerase II is not required in basal transcription," Nature, vol. 363, no. 6427, pp. 371-374, 1993.

[30] L. Schaeffer, R. Roy, S. Humbert et al., "DNA repair helicase: a component of BTF2 (TFIIH) basic transcription factor," Science, vol. 259, no. 5104, pp. 58-63, 1993.

[31] M. Johnston, "Feasting, fasting and fermenting: glucose sensing in yeast and other cells," Trends in Genetics, vol. 15, no. 1, pp. 29-33, 1999.

[32] E. Koutelou, C. L. Hirsch, and S. Y. R. Dent, "Multiple faces of the SAGA complex," Current Opinion in Cell Biology, vol. 22, no. 3, pp. 374-382, 2010.

[33] S. Rodriguez-Navarro, "Insights into SAGA function during gene expression," EMBO Reports, vol. 10, no. 8, pp. 843-850, 2009.

[34] A. M. Dudley, C. Rougeulle, and F. Winston, "The Spt components of SAGA facilitate TBP binding to a promoter at a post-activator-binding step in vivo," Genes and Development, vol. 13, no. 22, pp. 2940-2945, 1999.

[35] R. Belotserkovskaya, D. E. Sterner, M. Deng, M. H. Sayre, P. M. Lieberman, and S. L. Berger, "Inhibition of TATA-binding protein function by SAGA subunits Spt3 and Spt8 at Gcn4activated promoters," Molecular and Cellular Biology, vol. 20, no. 2, pp. 634-647, 2000.

[36] S. R. Bhaumik and M. R. Green, "SAGA is an essential in vivo target of the yeast acidic activator Gal4p," Genes and Development, vol. 15, no. 15, pp. 1935-1945, 2001.

[37] E. Larschan and F. Winston, "The S. cerevisiae SAGA complex functions in vivo as a coactivator for transcriptional activation by Gal4," Genes and Development, vol. 15, no. 15, pp. 19461956, 2001.

[38] H. Qiu, C. Hu, F. Zhang et al., "Interdependent recruitment of SAGA and Srb mediator by transcriptional activator Gcn4p," Molecular and Cellular Biology, vol. 25, no. 9, pp. 3461-3474, 2005.

[39] J. E. Brownell, J. Zhou, T. Ranalli et al., "Tetrahymena histone acetyltransferase A: a homolog to yeast Gcn5p linking histone acetylation to gene activation," Cell, vol. 84, no. 6, pp. 843-851, 1996.

[40] P. A. Grant, L. Duggan, J. Cote et al., "Yeast Gcn5 functions in two multisubunit complexes to acetylate nucleosomal histones: characterization of an ada complex and the saga (spt/ada) complex," Genes and Development, vol. 11, no. 13, pp. 16401650, 1997.

[41] P. A. Grant, D. Schieltz, M. G. Pray-Grant et al., "A subset of TAF(II)s are integral components of the SAGA complex required for nucleosome acetylation and transcriptional stimulation," Cell, vol. 94, no. 1, pp. 45-53, 1998.

[42] R. T. Utley, K. Ikeda, P. A. Grant et al., "Transcriptional activators direct histone acetyltransferase complexes to nucleosomes," Nature, vol. 394, no. 6692, pp. 498-502, 1998.

[43] C. Desmoucelles, B. Pinson, C. Saint-Marc, and B. DaignanFornier, "Screening the yeast "Disruptome" for mutants affecting resistance to the immunosuppressive drug, mycophenolic acid," Journal of Biological Chemistry, vol. 277, no. 30, pp. 27036-27044, 2002.

[44] C. K. Govind, F. Zhang, H. Qiu, K. Hofmeyer, and A. G. Hinnebusch, "Gcn5 promotes acetylation, eviction, and methylation of nucleosomes in transcribed coding regions," Molecular Cell, vol. 25, no. 1, pp. 31-42, 2007.

[45] A. Wyce, K. W. Henry, S. L. Berger, Verdin, Gu, and Yao, "H2B ubiquitylation and de-ubiquitylation in gene activation," Novartis Foundation Symposium, vol. 259, pp. 63-73, 2004.

[46] P. Pascual-García, C. K. Govind, E. Queralt et al., "Sus1 is recruited to coding regions and functions during transcription elongation in association with SAGA and TREX2," Genes and Development, vol. 22, no. 20, pp. 2811-2822, 2008.

[47] V. M. Weake, J. O. Dyer, C. Seidel et al., "Post-transcription initiation function of the ubiquitous SAGA complex in tissuespecific gene activation," Genes \& Development, vol. 25, pp. 1499-1509, 2011.

[48] M. Morillo-Huesca, M. Vanti, and S. Chávez, "A simple in vivo assay for measuring the efficiency of gene length-dependent processes in yeast mRNA biogenesis," FEBS Journal, vol. 273, no. 4, pp. 756-769, 2006.

[49] M. Sanso, I. Vargas-Perez, L. Quintales, F. Antequera, J. Ayte, and E. Hidalgo, "Gcn5 facilitates Pol II progression, rather than recruitment to nucleosome-depleted stress promoters, in Schizosaccharomyces pombe," Nucleic Acids Research, vol. 39, no. 15, pp. 6369-6379.

[50] K. W. Henry, A. Wyce, W. S. Lo et al., "Transcriptional activation via sequential histone $\mathrm{H} 2 \mathrm{~B}$ ubiquitylation and deubiquitylation, mediated by SAGA-associated Ubp8," Genes and Development, vol. 17, no. 21, pp. 2648-2663, 2003.

[51] J. A. Daniel, M. S. Torok, Z. W. Sun et al., "Deubiquitination of histone $\mathrm{H} 2 \mathrm{~B}$ by a yeast acetyltransferase complex regulates transcription," Journal of Biological Chemistry, vol. 279, no. 3, pp. 1867-1871, 2004.

[52] H. M. Bourbon, "Comparative genomics supports a deep evolutionary origin for the large, four-module transcriptional mediator complex," Nucleic Acids Research, vol. 36, no. 12, pp. 3993-4008, 2008. 
[53] K. D. Meyer, S. C. Lin, C. Bernecky, Y. Gao, and D. J. Taatjes, "P53 activates transcription by directing structural shifts in Mediator," Nature Structural and Molecular Biology, vol. 17, no. 6, pp. 753-760, 2010.

[54] J. A. Davis, Y. Takagi, R. D. Kornberg, and F. J. Asturias, “Structure of the yeast RNA polymerase II holoenzyme: mediator conformation and polymerase interaction," Molecular Cell, vol. 10, no. 2, pp. 409-415, 2002.

[55] G. Cai, T. Imasaki, K. Yamada, F. Cardelli, Y. Takagi, and F. J. Asturias, "Mediator Head module structure and functional interactions," Nature Structural and Molecular Biology, vol. 17, no. 3, pp. 273-279, 2010.

[56] H. Sakurai and T. Fukasawa, "Functional connections between mediator components and general transcription factors of Saccharomyces cerevisiae," Journal of Biological Chemistry, vol. 275, no. 47, pp. 37251-37256, 2000.

[57] C. Esnault, Y. Ghavi-Helm, S. Brun et al., "Mediator-dependent recruitment of TFIIH modules in preinitiation complex," Molecular Cell, vol. 31, no. 3, pp. 337-346, 2008.

[58] R. K. Biddick, G. L. Law, K. K. B. Chin, and E. T. Young, "The transcriptional coactivators SAGA, SWI/SNF, and mediator make distinct contributions to activation of glucose-repressed genes," Journal of Biological Chemistry, vol. 283, no. 48, pp. 33101-33109, 2008.

[59] Y. J. Kim, S. Bjorklund, Y. Li, M. H. Sayre, and R. D. Kornberg, "A multiprotein mediator of transcriptional activation and its interaction with the C-terminal repeat domain of RNA polymerase II," Cell, vol. 77, no. 4, pp. 599-608, 1994.

[60] G. Wang, M. A. Balamotis, J. L. Stevens, Y. Yamaguchi, H. Handa, and A. J. Berk, "Mediator requirement for both recruitment and postrecruitment steps in transcription initiation," Molecular Cell, vol. 17, no. 5, pp. 683-694, 2005.

[61] J. Soutourina, S. Wydau, Y. Ambroise, C. Boschiero, and M. Werner, "Direct interaction of RNA polymerase II and mediator required for transcription in vivo," Science, vol. 331, no. 6023, pp. 1451-1454, 2011.

[62] J. A. Fischbeck, S. M. Kraemer, and L. A. Stargell, "SPN1, a conserved gene identified by suppression of a postrecruitment-defective yeast TATA-binding protein mutant," Genetics, vol. 162, no. 4, pp. 1605-1616, 2002.

[63] V. Pujari, C. A. Radebaugh, J. V. Chodaparambil et al., "The transcription factor Spn 1 regulates gene expression via a highly conserved novel structural motif," Journal of Molecular Bio$\log y$, vol. 404, no. 1, pp. 1-15, 2010.

[64] D. L. Lindstrom, S. L. Squazzo, N. Muster et al., "Dual roles for Spt5 in pre-mRNA processing and transcription elongation revealed by identification of Spt5-associated proteins," Molecular and Cellular Biology, vol. 23, no. 4, pp. 1368-1378, 2003.

[65] N. J. Krogan, M. Kim, S. H. Ahn et al., "RNA polymerase II elongation factors of Saccharomyces cerevisiae: a targeted proteomics approach," Molecular and Cellular Biology, vol. 22, no. 20, pp. 6979-6992, 2002.

[66] A. C. Gavin, M. Bösche, R. Krause et al., "Functional organization of the yeast proteome by systematic analysis of protein complexes," Nature, vol. 415, no. 6868, pp. 141-147, 2002.

[67] S. M. Yoh, H. Cho, L. Pickle, R. M. Evans, and K. A. Jones, "The Spt6 SH2 domain binds Ser2-P RNAPII to direct Iws1dependent mRNA splicing and export," Genes and Development, vol. 21, no. 2, pp. 160-174, 2007.

[68] K. Tarassov, V. Messier, C. R. Landry et al., "An in vivo map of the yeast protein interactome," Science, vol. 320, no. 5882, pp. 1465-1470, 2008.
[69] L. Li, H. Ye, H. Guo, and Y. Yin, "Arabidopsis IWS1 interacts with transcription factor BES1 and is involved in plant steroid hormone brassinosteroid regulated gene expression," Proceedings of the National Academy of Sciences of the United States of America, vol. 107, no. 8, pp. 3918-3923, 2010.

[70] A. Bortvin and F. Winston, "Evidence that Spt6p controls chromatin structure by a direct interaction with histones," Science, vol. 272, no. 5267, pp. 1473-1476, 1996.

[71] C. D. Kaplan, L. Laprade, and F. Winston, "Transcription elongation factors repress transcription initiation from cryptic sites," Science, vol. 301, no. 5636, pp. 1096-1099, 2003.

[72] M. W. Adkins and J. K. Tyler, "Transcriptional activators are dispensable for transcription in the absence of Spt6-mediated chromatin reassembly of promoter regions," Molecular Cell, vol. 21, no. 3, pp. 405-416, 2006.

[73] S. M. Yoh, J. S. Lucas, and K. A. Jones, "The Iws1:Spt6:CTD complex controls cotranscriptional mRNA biosynthesis and HYPB/Setd2-mediated histone H3K36 methylation," Genes and Development, vol. 22, no. 24, pp. 3422-3434, 2008.

[74] M. B. Ardehali, J. Yao, K. Adelman et al., "Spt6 enhances the elongation rate of RNA polymerase II in vivo," EMBO Journal, vol. 28, no. 8, pp. 1067-1077, 2009.

[75] S. M. McDonald, D. Close, H. Xin, T. Formosa, and C. P. Hill, "Structure and biological importance of the Spn1-Spt6 interaction, and its regulatory role in nucleosome binding," Molecular Cell, vol. 40, no. 5, pp. 725-735, 2010.

[76] I. Ivanovska, P. -É. Jacques, O. J. Rando, F. Robert, and F. Winston, "Control of chromatin structure by Spt6: different consequences in coding and regulatory regions," Molecular and Cellular Biology, vol. 31, no. 3, pp. 531-541, 2011.

[77] M. Endoh, W. Zhu, J. Hasegawa et al., "Human Spt6 stimulates transcription elongation by RNA polymerase II in vitro," Molecular and Cellular Biology, vol. 24, no. 8, pp. 3324-3336, 2004.

[78] M. L. Diebold, M. Koch, E. Loeliger et al., "The structure of an Iws1/Spt6 complex reveals an interaction domain conserved in TFIIS, Elongin A and Med26," EMBO Journal, vol. 29, no. 23, pp. 3979-3991, 2010.

[79] L. Neigeborn, K. Rubin, and M. Carlson, "Suppressors of SNF2 mutations restore invertase derepression and cause temperature-sensitive lethality in yeast," Genetics, vol. 112, no. 4, pp. 741-753, 1986.

[80] Y. Lorch, B. Maier-Davis, and R. D. Kornberg, "Chromatin remodeling by nucleosome disassembly in vitro," Proceedings of the National Academy of Sciences of the United States of America, vol. 103, no. 9, pp. 3090-3093, 2006.

[81] M. W. Adkins, S. K. Williams, J. Linger, and J. K. Tyler, "Chromatin disassembly from the PHO5 promoter is essential for the recruitment of the general transcription machinery and coactivators," Molecular and Cellular Biology, vol. 27, no. 18, pp. 6372-6382, 2007.

[82] T. Gkikopoulos, K. M. Havas, H. Dewar, and T. Owen-Hughes, "SWI/SNF and Asf1p cooperate to displace histones during induction of the Saccharomyces cerevisiae HO promoter," Molecular and Cellular Biology, vol. 29, no. 15, pp. 4057-4066, 2009.

[83] P. Korber, S. Barbaric, T. Luckenbach et al., "The histone chaperone Asf1 increases the rate of histone eviction at the yeast PHO5 and PHO8 promoters," Journal of Biological Chemistry, vol. 281, no. 9, pp. 5539-5545, 2006.

[84] S. Takahata, Y. Yu, and D. J. Stillman, "FACT and Asf1 regulate nucleosome dynamics and coactivator binding at the $\mathrm{HO}$ promoter," Molecular Cell, vol. 34, no. 4, pp. 405-415, 2009. 
[85] M. A. Schwabish and K. Struhl, "The Swi/Snf complex is important for histone eviction during transcriptional activation and RNA polymerase II elongation in vivo," Molecular and Cellular Biology, vol. 27, no. 20, pp. 6987-6995, 2007.

[86] S. Shivaswamy and V. R. Iyer, "Stress-dependent dynamics of global chromatin remodeling in yeast: dual role for SWI/SNF in the heat shock stress response," Molecular and Cellular Bio$\log y$, vol. 28, no. 7, pp. 2221-2234, 2008.

[87] S. R. Collins, K. M. Miller, N. L. Maas et al., "Functional dissection of protein complexes involved in yeast chromosome biology using a genetic interaction map," Nature, vol. 446, no. 7137, pp. 806-810, 2007.

[88] A. Roguev, S. Bandyopadhyay, M. Zofall et al., "Conservation and rewiring of functional modules revealed by an epistasis map in fission yeast," Science, vol. 322, no. 5900, pp. 405-410, 2008.

[89] L. Gao and D. S. Gross, "Sir2 silences gene transcription by targeting the transition between RNA polymerase II initiation and elongation," Molecular and Cellular Biology, vol. 28, no. 12, pp. 3979-3994, 2008.

[90] A. Mayer, M. Lidschreiber, M. Siebert, K. Leike, J. Söding, and P. Cramer, "Uniform transitions of the general RNA polymerase II transcription complex," Nature Structural and Molecular Biology, vol. 17, no. 10, pp. 1272-1278, 2010.

[91] L. A. Lebedeva, E. N. Nabirochkina, M. M. Kurshakova et al., "Occupancy of the Drosophila hsp70 promoter by a subset of basal transcription factors diminishes upon transcriptional activation," Proceedings of the National Academy of Sciences of the United States of America, vol. 102, no. 50, pp. 18087-18092, 2005.

[92] J. M. Park, J. Werner, J. M. Kim, J. T. Lis, and Y. J. Kim, "Mediator, not holoenzyme, is directly recruited to the heat shock promoter by HSF upon heat shock," Molecular Cell, vol. 8, no. 1, pp. 9-19, 2001.

[93] D. A. Gilchrist, G. Dos Santos, D. C. Fargo et al., "Pausing of RNA polymerase II disrupts DNA-specified nucleosome organization to enable precise gene regulation," Cell, vol. 143, no. 4, pp. 540-551, 2010. 

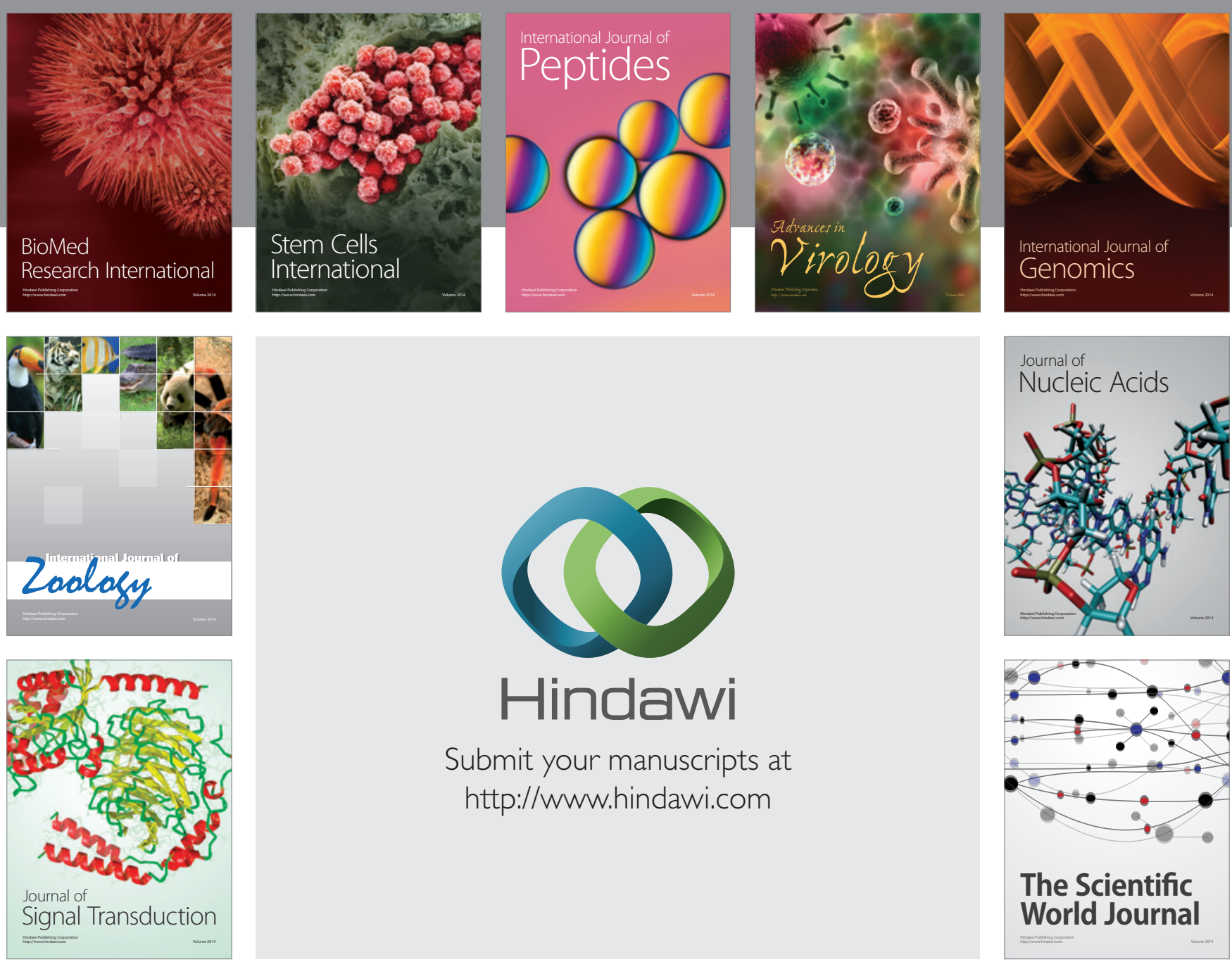

Submit your manuscripts at

http://www.hindawi.com
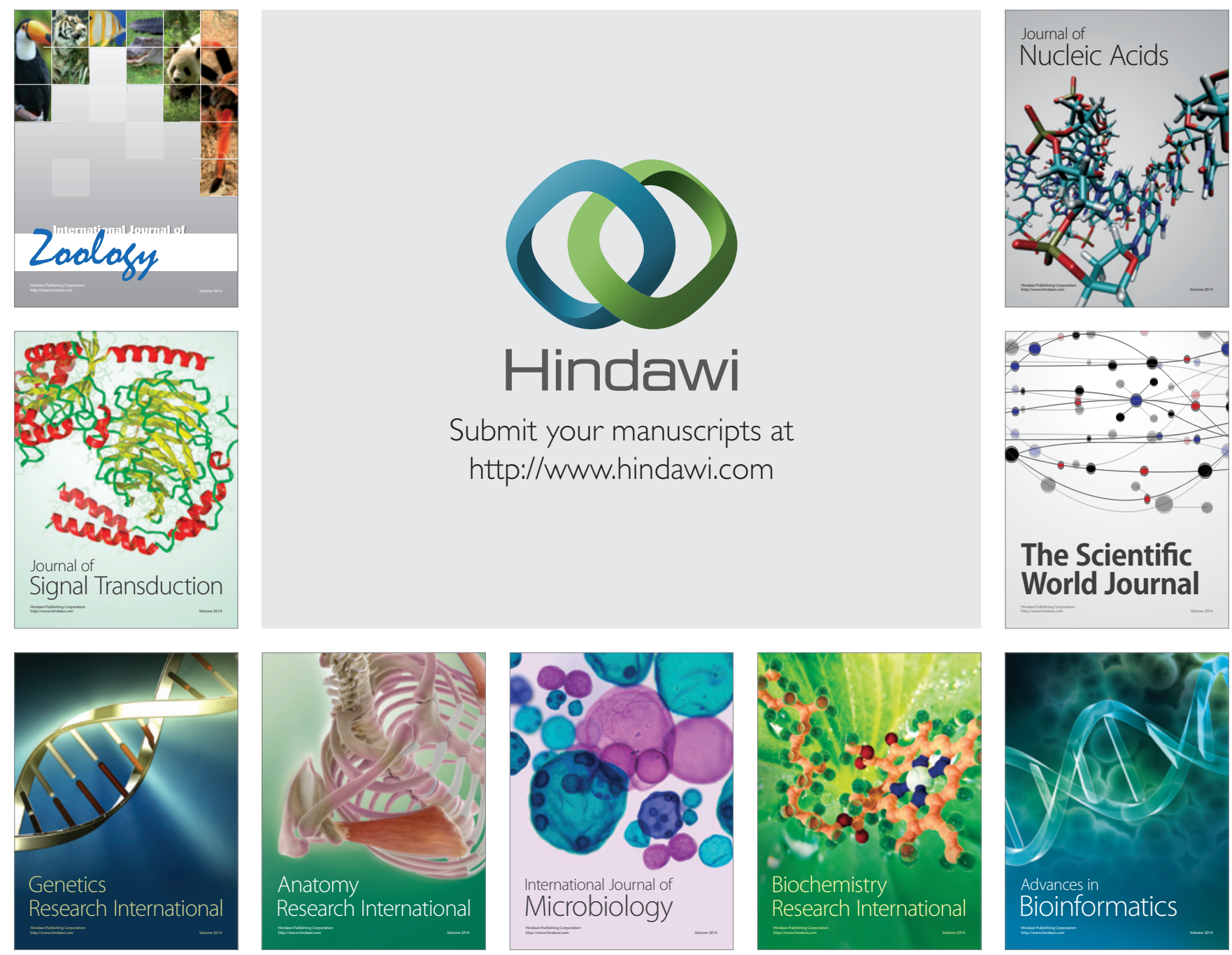

The Scientific World Journal
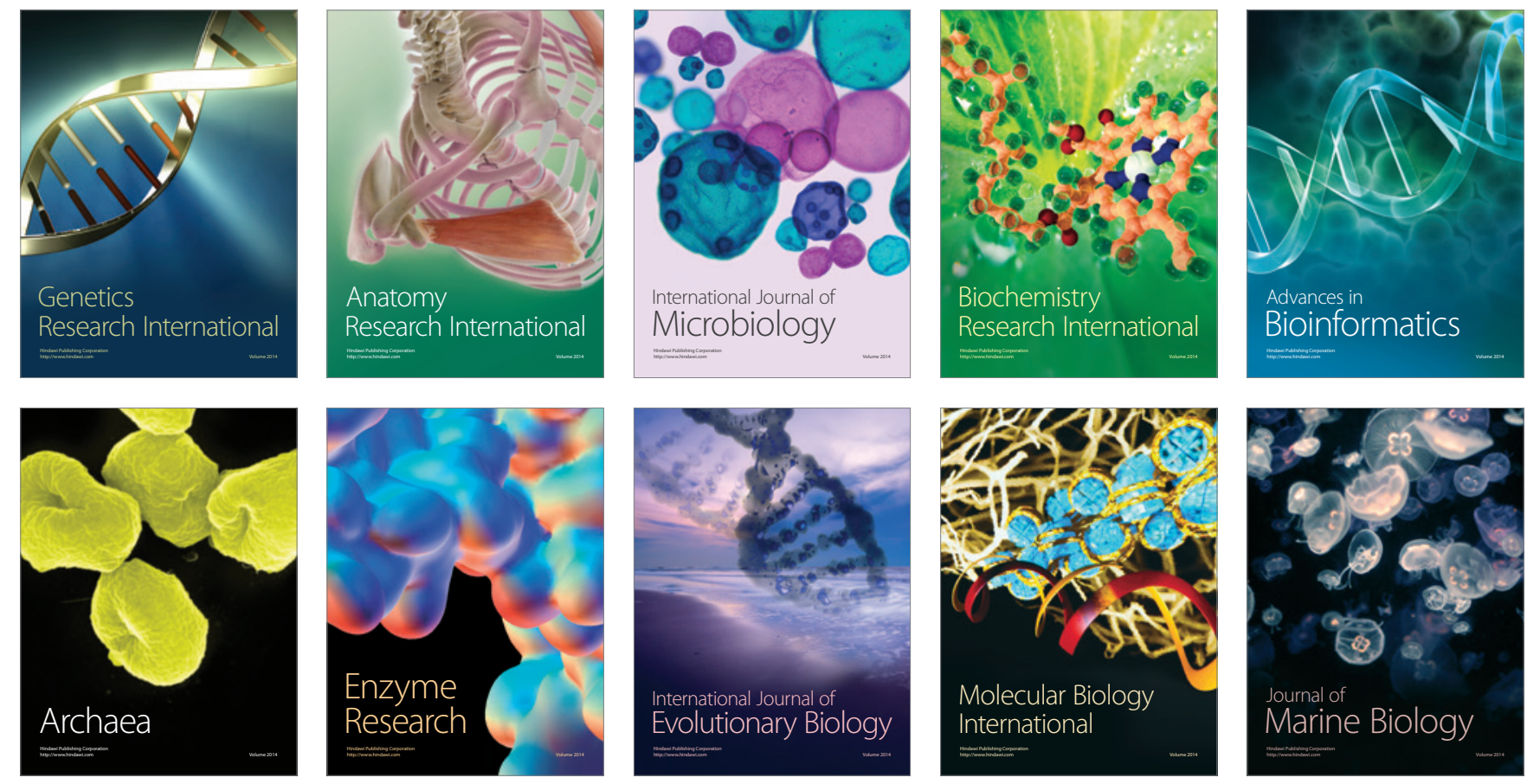